\title{
The Wolfson Foundation
}

\section{5 years of philanthropy}

An independent grant-making charity based in Central London, Wolfson Foundation has awarded some $f 1$ billion to more than 14,000 projects in the UK from Cornwall to the Shetland Islands since its establishment in the making is at the heart of what they do, and how they've adapted in the face of a global pandemic.

\section{T}

Wolfson Foundation is a grant-making charity that has education in the United Kingdom for over 60 years. It is now facing one of its biggest challenges to date: the effect of the Coronavirus pandemic on educational and cultural organisations across the country.

In this interview with Chief Executive Paul Ramsbottom, Research Outreach found out more about the foundation's mission, what sort of projects it funds and why, and how it is helping cultural organisations in particular navigate the

What is the mission of

We are a charitable foundation with about $f 900$ million under invertment. We allocate funding of $f 30-40$ million a year and the aim is to fund research and education in British society. Within that we've got a couple of 'sub-aims': there's a real emphasis on high-quality research and education. Perhaps what makes us distinctive, and what we're best known for, is that about $85 \%$ of our funding is for infrastructure: buildings, refurbishment and equipment. The rest of the funding is for people and includes scholarships, fellowships and bursaries.

We were set up by the Wolfson family in the 1950s, Isaac Wolfson was a the Jewish Pale of Settlement in the 1890s and built a fortune from more or less nothing. In the 1950s the family and so here we are more than 60 years later. What we try to do as an organisation is to have all the rigour and analysis and detachment of a Research Council but to retain that involvement and colour that comes

How did you come to be involved in

the foundation personally?

just over a decade. My academic background is in history. I did history at Oxford University, and I've and public benefit.

How do you decide which.

rrganisations or projects to

We've got a strategic framework and a thoughtful board, who frame a broad picture. Within that we are very much concerned with listening to the sectors in which we work, and we talk to the whin informally and formally through an anonymised applicant survey. We also have expert panels, which advise the trustees and the executive team in each the areas that we work

In terms of what we fund, project by project, we run what you would think wanted to give back to British society undergraduate and postgraduate and the overlap between private mopy

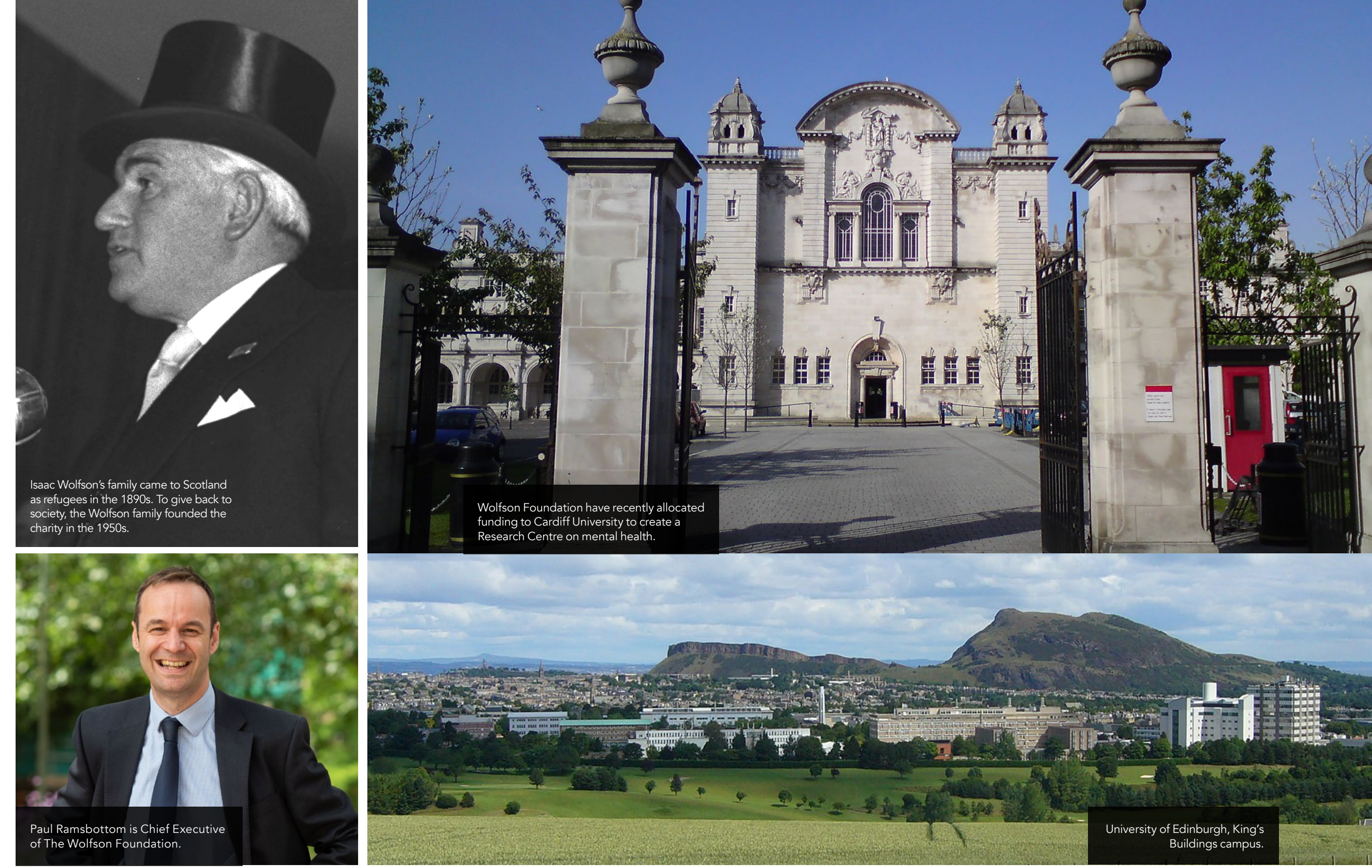

of as a pretty standard, although For example, if we have a big rystem. infrastructure proposal to consider, we go out for peer review and work with around six or seven reviewers the UK and internationally. Then we go through a process of feedback. for the applicants, we have an expert panel meeting, and then make recommendations to the board. Tha academic model of decision-making is one that we then filter out across all our areas of working. The three big types of organisations that we fund a universilies, schools and cultura institutions (museums, galleries, performing arts, heritage organisations, public engagement with science organisations). We also support front-

The first thing we did when the storm broke in March was to make all of our grants very flexible.
Can you give me an example of
a project that you are fond of?

Like a lot of organisations, we've been concerned about mental health within British society and what appears to be increasing rates of mental healt challenges, especially for younger people. It's an area in the UK that in terms of research. A couple of years ago, we announced a $f 10$ million initiative. We put together an international panel of experts and appears to have been under-invested the UK. We allocated the funding to Cardiff for a really imaginative proposal: they have created a Research Centre on mental health, working with partners across Wales, was a giant knd of incubator. It's too early a feel personally quite proud of. That's quality research in a ination, high (from more basic to more clinical across Wales. science) and grassroots partnerships

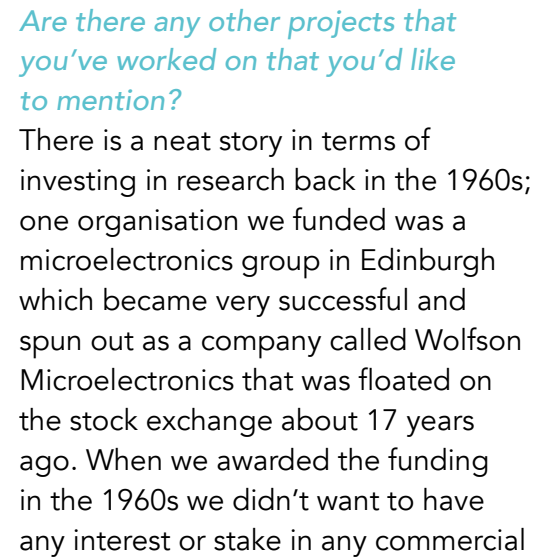

is a neat story in terms of spun out as a company called Wolfson go. When we awarded the funding any interest or stake in any commercial 


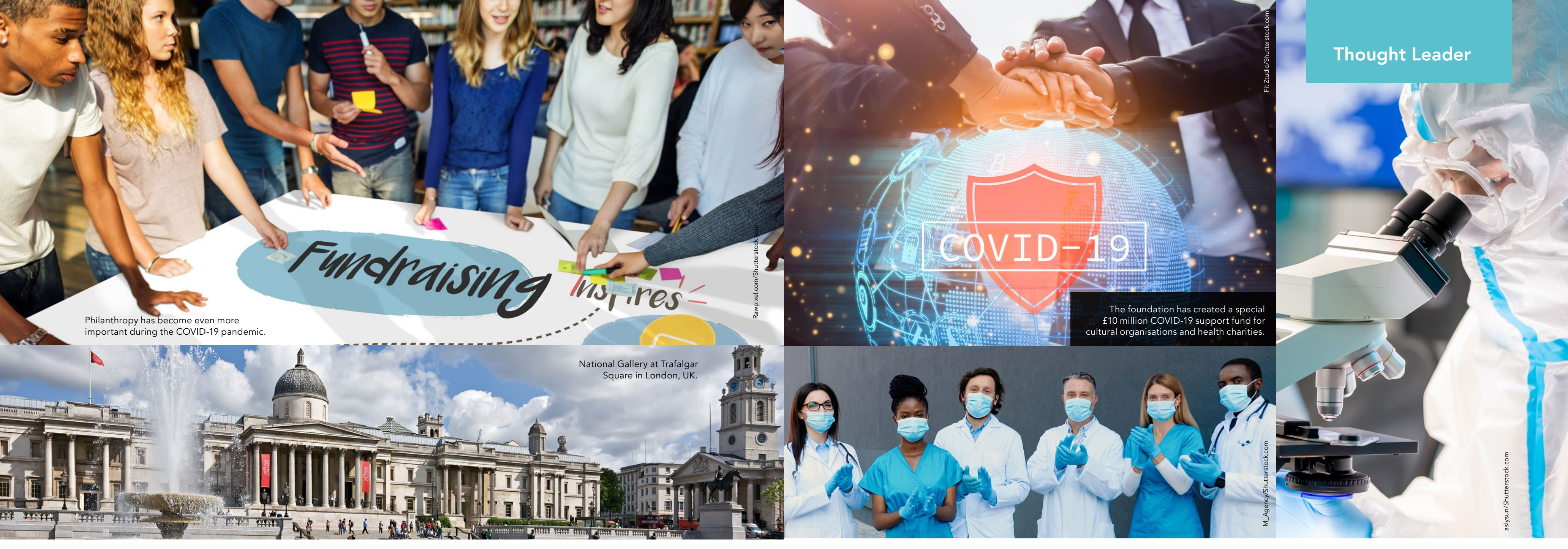

spin-off, but a proportion of those profits have been ploughed back
into the University of Edinburgh into the University of Edinburgh for
really bright individuals doing PhDs in microelectronics.

Did you observe increased demand for funding as a result of COVID-19
How do you deal with that?

It has been an extraordinary period. When you have a portfolio of partners through a challenging time. What's unique about 2020 is that almost organisation we work with is going through a crisis of one sort or another. We've divided up our thinking in terms of mainstream education organisations on the one hand and cultural organisations and health charities on the other.

The first thing we did when the storm broke in March was to make all of our grants very flexible. We relaxed a lot of the conditions on reporting, the time period to claim and so on. For organisations that were most challenged (a lot of the
cultural organisations), we simply paid out grants immediately. We made a record payment in April 2020 that was
higher than any other month in the foundation's long history.

The more difficult thing has been thinking about what you do in terms of new funding. The foundation's view is that a time of crisis is a time
to increase our spending. This might tom slightly counterintuitiv bight investment levels for our endowment are bouncing around in quite a dramatic fashion. But as a long-term funder, the responsible thing to do has been to maintain and even increase our funding. Part of what we're doing is to say to universities and to schools that we hope to be a constant feature in a moving world. In terms of our infrastructure-funding programme for schools and universities, we want to be there responding to their needs, and for them to know that whatever else is happening, and whatever other income streams are dropping and changing, Wolson Foundation is sticking with it. Alongside continuing we've also created a special f10 million
COVID-19 support fund for cultural organisations and health charities that's about rapid response, unrestricted funding that allows those organisations to use flexible money to do whatever they need to do to help them through the winter and to rethink as they're reopening to audiences. Regional museums, regional performing arts venues, frontine health charities: with over the last few $y$ bers warking eligible to come in for that fund.

What other organisations do you work with and how do you work with them? Partnership is hardwired into everything. We are always asking: are there other funders or expert partners that we should be working with? Sometimes it's simply other funders and partnership where we're both putting money in and working together; we've worked quite extensively with the Wellcome Trus over the years, for example. Another model is one in which we work with an expert body such as the Royal Society we are providing the funding while

What's the role of philanthropy in society? It may be more important in the next two or three years than it has ever been before.

our partners provide the expertise and administration. Thirdly, we're a funding organisation who work directy with government We have a small with gov of programmes were all actually directly partnering with central government We feel very passionately that the best way to have an impact and achieve outcomes is by working with others.

What are the future plans for The Wolfson Foundation?
The big and interesting challenge The big and interesting challenge
for us for 2021 will be the extent to which we attempt to move our funding back to where it was in 2019 or how we keep going with the COVD-19 we will still be focused on research infrastructure and for the other areas of our funding there is that question still to be asked. We may come up dh a hybrid model where we try and and a bit of more flexible support. The other thing that's quite interesting (and that goes beyond the Covid response) is: what you can do as a funder beyond simply paying out money?

For example, you've got convening power to get people around the table to discuss issues, you can commission your own policy pieces. You've got your investments and what you do with those. We've just announced that we for sxample, which, as well as fon, for example, which, as well as funding statement.
The final thing that I've been quite een for the foundation to do is to get involved in some of the debates round the role of philanthropy, which has become more important during the COVID-19 pandemic. What's the ole of philanthropy in society? It may be more important in the next two or three years than it has ever en before.

TheWolfson* Foundation W: wolfson.org.u 